\title{
VORSCHAU $01>$
}

\section{ENTWICKLUNG}

Testen von Fahrerassistenzsystemen bei maximaler Safety \& Security

\section{Reifendruck-Messsystem der neuesten Generation}

\section{E/E-Architektur für zeitkritische} Funktionen

\section{Optimierung von Schriften in Bedienanzeigen}

Zuverlässige Fahrzeugortung für sichere Car-to-X-Kommunikation im Nahfeld

Validierung von Steuergeräte-Software im virtuellen Fahrversuch

\section{FORSCHUNG}

Radarsensormodell für den virtuellen Entwicklungsprozess

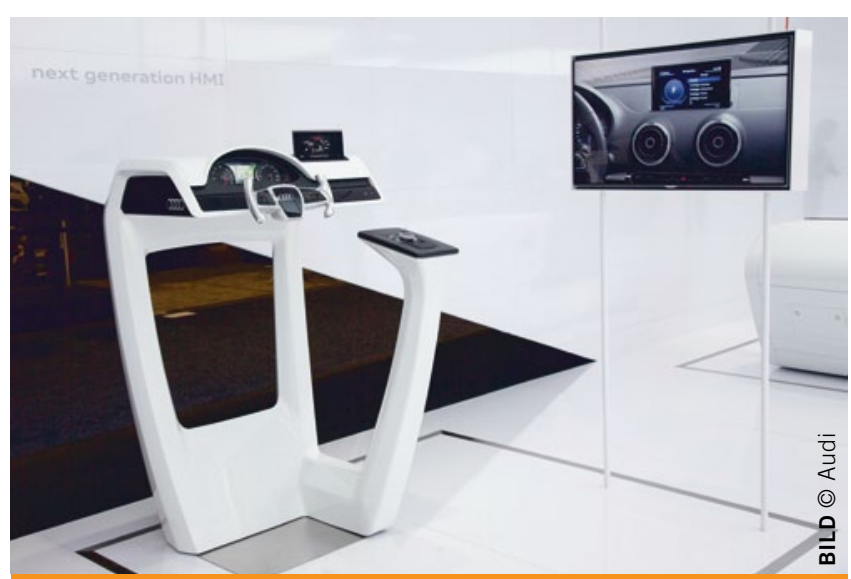

\section{TITELTHEMA}

\section{CONSUMER-ELEKTRONIK UND IT}

Die Arbeitsgruppe zur aktiven Standardisierung der Schnittstellen von mobilen Endgeräten „Consumer Electronics for Automotive“ agiert seit 2007 aktiv im Trend der ConsumerElektronik. Herstellerübergreifend folgt die Autoindustrie damit dem Trend, mobile Endgeräte aus dem Bereich der Kommunikations- und Unterhaltungselektronik im Fahrzeug anzubinden und zu integrieren. ATZelektronik fasst die aktuellen Ergebnisse der Arbeitsgruppen zusammen und stellt deren nächste Ziel vor. Ein Artikel von Daimler gibt Ausblicke auf die nächste Generation von Nutzfahrzeug-Infotainmentsystemen unter dem Begriff Extended Vehicle. Mit Dirk Wollschläger, dem Leiter der Geschäftseinheit Automobil bei IBM, werden Safetyund IT-Security-Maßnahmen im vernetzten Fahrzeug erörtert. 